\title{
A comparison of two methods for estimating odds ratios: Results from the National Health Survey Enayatollah Bakhshi ${ }^{1}$, Mohammad R Eshraghian ${ }^{1}$, Kazem Mohammad ${ }^{* 1}$ and Behjat Seifi ${ }^{2}$
}

Address: ${ }^{1}$ Department of Biostatistics, School of Public Health and Institute of Public Health Research, Tehran University/Medical Sciences, Iran and ${ }^{2}$ Department of Physiology, Medicine School, Tehran University/Medical Sciences, Iran

Email: Enayatollah Bakhshi - Bakhshi@razi.tums.ac.ir; Mohammad R Eshraghian - eshraghian@yahoo.com; Kazem Mohammad* - mohamadk@tums.ac.ir; Behjat Seifi - behins@yahoo.com

* Corresponding author

Published: 25 November 2008

BMC Medical Research Methodology 2008, 8:78 doi:10.1186/147I-2288-8-78

This article is available from: http://www.biomedcentral.com/147I-2288/8/78

(c) 2008 Bakhshi et al; licensee BioMed Central Ltd.

This is an Open Access article distributed under the terms of the Creative Commons Attribution License (http://creativecommons.org/licenses/by/2.0), which permits unrestricted use, distribution, and reproduction in any medium, provided the original work is properly cited.
Received: 6 July 2008

Accepted: 25 November 2008

\begin{abstract}
Background: The practice of dichotomizing a continuous outcome variable does not make use of within-category information. That means the loss of information. This study compared two approaches in the modelling of the association between sociodemographic and smoking with obesity in adult women in Iran.
\end{abstract}

Methods: We conducted a comparative study between two methods via an illustrative example, using data from the "National Health Survey in Iran (NHSI)" database. It included I4I76 women aged 20-69 years. At first, body mass index(BMI) was treated as a continuous variable, $\mathrm{OR}_{\mathrm{s}}$ and 95 per cent confidence intervals were calculated using the "without dichotomizing" method. Then subjects were classified into obese $\left(B M I \geq 30 \mathrm{~kg} / \mathrm{m}^{2}\right)$ and nonobese $\left(\mathrm{BMI}<30 \mathrm{~kg} / \mathrm{m}^{2}\right)$ and logistic regression model was used to estimate $\mathrm{OR}_{\mathrm{s}}$ and 95 per cent confidence intervals.

Results: The odds ratio estimates changed only slightly over the two methods. But the "without dichotomizing" method provided shorter confidence intervals on the odds ratio parameters than dichotomizing method. All relative confidence interval lengths were greater than I.I5.

Conclusion: If responses are continuous then the "without dichotomizing" method is certainly more useful than the "dichotomizing" method and leads to more precise estimation of odds ratios.

\section{Background}

Over the past 20 years, the logistic regression model has become more common. The parameter in logistic regression has the interpretation of log odds ratio, which is easy for people such as physicians to understand. This model uses a categorical (dichotomous or polytomous) outcome variable. In many areas of research, the outcome data are continuous. Many researchers have no hesitation in dichotomizing a continuous variable but this practice does not make use of within-category information. Sev- eral investigators have noted the disadvantages of dichotomizing [1-9].

Although Goldwasser and Fitzmaurice [10] stated that a 'direct comparison of the logistic and linear regression coefficients is not meaningful since they have different interpretations, Moser and Coombs [11] provided a closed form relationship that allows a direct comparison between the logistic and linear regression coefficients. They also provided a procedure that allows the researcher 
to analyze the original continuous outcome without dichotomizing.

The aims of this paper are: (1) to demonstrate that the coefficient estimates from the "without dichotomizing (WDICH)" method have smaller variances and shorter confidence intervals than the dichotomizing (DICH) method; and (2) to find more efficient parameter estimates than logistic regression model for the association of sociodemographic and smoking with obesity by using cross-sectional data from the 1999-2000 National Health Survey in Iran.

\section{Methods}

\section{Overview of WDICH method}

The WDICH method overcomes some of the disadvantages of logistic regression model [11]. The linear regression model can be stated as follows:

$$
y_{i}=x_{i}^{\prime} \beta+e_{i}
$$

Where $e_{i}$ is random error term with mean 0 and variance $\sigma^{2}>0 ; e_{i}$ and $e_{j}$ are uncorrelated so that the covariance $\left(e_{i^{\prime}}\right.$ $\left.e_{j}\right)=0$ for all $i, j ; i \neq j$. Moser and Coombs supposed that the random terms $e_{i}$ follow a logistic distribution and explanatory variables $x_{i}$ follow a discrete uniform distribution. They provided an estimate of the same odds ratio parameter as the DICH method, but without loss of information [11]. The estimates obtained from WDICH are more efficient than those from the logistic model [11]. They also carried out an extensive simulation study to evaluate the robustness of this conclusion to changes in the distributions of $e_{i}$ and $x_{i}$ [11]. The reliability of these simulation results is assessed in this paper.

\section{Data set examined}

The NHSI is a survey designed to gain comprehensive knowledge and information about health care problems and difficulties throughout in Iran, 1999-2000. Data from the NHSI were considered in this investigation. In this study, 14176 women, 8957 urban and 5219 rural aged 20-69 years were investigated. We excluded pregnant women from the analyses. This study is approved by the Ethic Committee of the Tehran University of Medical Sciences.

\section{Model variables}

a) Response variable

Height and weight were measured rather than selfreported. BMI (Body Mass Index) was calculated as weight in kilograms divided by the square of the height in meters $\left(\mathrm{kg} / \mathrm{m}^{2}\right)$, and subjects were classified into obese (BMI $\geq 30$ $\left.\mathrm{kg} / \mathrm{m}^{2}\right)$ and nonobese $\left(\mathrm{BMI}<30 \mathrm{~kg} / \mathrm{m}^{2}\right)$.

\section{b) Independent variables}

i. Place of residence: Urban (1) or Rural (0); ii. Age (yr);

iii. Education: The total number of years of education;

iv. Smoking status: Smoker (1) or Nonsmoker (0);

v. Marital status: Married (1) or Non-married (0);

vi. Economic index: Economic index was defined as square meter of living place divided by number of household. Participants were classified by their economy index status into four classes: 1 ) low (economic index $\leq$ Quartile 1 ), 2) lower-middle (Quartile $1<$ economic index $\leq$ Quartile 2), 3) upper-middle (Quartile $2<$ economic index $\leq$ Quartile 3) and 4) high (economic index > Quartile 3).

\section{Statistical analysis}

At first, BMI was treated as a continuous variable and is expressed as a function of place of residence, age, education, smoking, marital status and economic index using the WDICH method, $\mathrm{OR}_{\mathrm{s}}$ and 95 per cent confidence intervals were calculated. Then subjects were classified into obese $\left(\mathrm{BMI} \geq 30 \mathrm{~kg} / \mathrm{m}^{2}\right)$ and nonobese (BMI $<30 \mathrm{~kg} /$ $\mathrm{m}^{2}$ ) and logistic regression model was used to estimate $\mathrm{OR}_{\mathrm{s}}$ and 95 per cent confidence intervals.

Two methods were compared with respect to relative confidence interval length of parameter estimates.

Analyses results were obtained using STATA (Version 8.0) and $\mathrm{R}$ (Version 2.0.1).

\section{Results}

Distribution of age, BMI, education, marital status, economic index and smoking are shown in table 1 in order to make the data presentation complete. The mean BMI of urban women was $26.02 \mathrm{~kg} / \mathrm{m}^{2}(95$ percent CI: $25.92-$ 26.12). The rural women had a mean BMI $24.14 \mathrm{~kg} / \mathrm{m}^{2}$ (95 percent CI: 24.02-24.26).

Results in Table 2 were obtained from fitting Models in DICH and WDICH methods. DICH and WDICH produced different confidence intervals, although the odds ratios were similar. The odds ratio estimate from the WDICH method had smaller variances and shorter confidence intervals than the DICH method. The mathematical proof and simulation results are found in Moser and Coombs [11].

\section{Explanation of results from Table 2 (WDICH)}

$\square$ Urban women had significantly higher odds of obesity than their rural counterparts (OR = 2.041, 95\% CI: 1.916 $-2.914)$.

$\square$ Age was directly associated with obesity (OR $=1.03$, 95\% CI: 1.026-1.032). 
Table I: Characteristics of the analytical sample by place of residence in 14176 Iranian women, 1999-2000

\begin{tabular}{|c|c|c|}
\hline Variables & Rural (n= 5219) & Urban $(n=8957)$ \\
\hline Age, years(mean, sda) & $36.91(13.58)$ & $37.3(13.6)$ \\
\hline $\mathrm{BMI}$ (mean, sd) & $24.14(4.64)$ & $26.02(5.06)$ \\
\hline Years of education(mean, sd) & $2.59(3.42)$ & $5.65(4.83)$ \\
\hline Married (number) & 3973 & 7234 \\
\hline Non-married (number) & 1246 & 1723 \\
\hline Low economic index(number) & 1655 & 2379 \\
\hline Lower-middle economic index(number) & 1036 & 2271 \\
\hline Upper-middle economic index(number) & 1280 & 2212 \\
\hline High economic index(number) & 1248 & 2095 \\
\hline Smoker (number) & 97 & 176 \\
\hline Non smoker(number) & 5122 & 8781 \\
\hline
\end{tabular}

astandard deviation

bBody mass index (weight $(\mathrm{kg}) /$ height $\left.(\mathrm{m})^{2}\right)$.

$\square$ Education was inversely associated with obesity $(\mathrm{OR}=$ 0.99, 95\% CI: 0.979-0.996).

$\square$ Non smoker women were more obese than smokers. Obesity odds ratio was 0.69 (95 percent CI: 0.553-0.856) for smoker women compared to non smokers.

Married women had significantly higher odds of obesity than their non-married counterparts (OR $=1.24,95 \%$ CI: $1.150-1.323)$.

$\square$ An association observed between economic index and obesity. Using low as the reference group, obesity odds ratios were 1.36 (95 percent CI: 1.246-1.475), 1.31 (95 percent CI: $1.205-1.426$ ) and 1.29 (95 percent CI: $1.155-$ 1.443) for the lower-middle, upper-middle and high groups respectively.

\section{Discussion}

Dichotomizing the primary outcome variable may result in loss of information. We conducted a comparative study between two methods via an illustrative example, using data from the NHSI database. It included 14176 women aged 20-69 years. OR estimates and 95 per cent confi- dence intervals were calculated using both the DICH method and WDICH method. Overall, we obtained similar parameter estimates from DICH and WDICH methods. But the odds ratio estimate from the WDICH method had smaller variances and shorter confidence intervals than the DICH method. Our results indicated the improvement of the WDICH method over the DICH method because for all covariates the relative confidence interval length was greater than 1.15. Our results were consistent with the findings by Moser and Coombs [11] showing the greater efficiency of parameter estimates from WDICH method in comparison to DICH method.

In our study, there was a positive association between age and obesity. Our results are consistent with most studies [12-15].

In most studies, women with lower education were more obese than those with higher education. Our results were consistent with these studies [16-20].

We observed an inverse association between smoking and obesity. Most studies report that smoking is associated

Table 2: Adjusted odds ratios for obesity and confidence intervals using two methods for the National Health Survey

\begin{tabular}{|c|c|c|c|c|}
\hline Covariates & Odds ratio & $\begin{array}{c}95 \% \mathrm{Cl}^{\mathrm{a}} \\
\text { (Without dichotomizing) }\end{array}$ & $\begin{array}{c}95 \% \mathrm{Cl} \\
\text { (dichotomizing) }\end{array}$ & $\begin{array}{c}\text { Relative length of } \mathrm{Cl} \\
\text { (dichotomizing/without dichotomizing) }\end{array}$ \\
\hline Place of residence & $2.04(2.13)^{\mathrm{b}}$ & $1.916-2.194$ & $1.915-2.369$ & 1.63 \\
\hline Age & $1.03(1.02)$ & $1.026-1.032$ & $1.017-1.026$ & 1.50 \\
\hline Years of education & $0.99(0.98)$ & $0.979-0.996$ & $0.968-0.993$ & 1.47 \\
\hline Smoking & $0.69(0.65)$ & $0.553-0.856$ & $0.468-0.916$ & 1.48 \\
\hline Marital status & $1.24(1.48)$ & I.I50-I.323 & $1.312-1.668$ & 2.06 \\
\hline Lower-middle economy index & $1.36(1.37)$ & $1.246-1.475$ & $1.206-1.554$ & 1.52 \\
\hline Upper-middle economy index & I.3I(I.29) & $1.205-1.426$ & $1.136-1.468$ & 1.50 \\
\hline High Economy Index & $1.29(1.25)$ & I.I55-I.443 & $1.094-1.425$ & 1.15 \\
\hline
\end{tabular}

${ }^{a}$ confidence interval

bwithout dichotomizing(dichotomizing) 
with lower relative weight [21-25]. Our findings are basically in line with these studies.

We found that non-married women were less likely to be obese than their married counterparts. Our results are consistent with most studies $[26,27]$.

We found a statistically significant association between economic index level and obesity for women. Women with low level were leaner than those with other levels. Our findings are consistent with some study in developing countries [28].

One of the limitations of this study is the cross-sectional nature of the NHSI dataset. This means that we cannot draw definitive conclusions concerning the direction of causality. It is another limitation that physical activity and income were not used in our investigation. The other limitation in this study is that marital status could be categorized into legally married and non-married only.

Our study had several strengths. It was performed in a nationally representative sample of the Iranian women. Height and weight were actually measured rather than self-reported. It is well known that self-reports underestimate the prevalence of obesity $[29,30]$.

\section{Conclusion}

WDICH method is useful to estimate odds ratios and provides more efficient parameter estimates than DICH method when responses are continuous. When outcome is a continuous variable, it should not be treated as a binary variable.

\section{Abbreviations}

BMI: body mass index; OR: odds ratio; NHSI: National Health Survey in Iran; WDICH: without dichotomizing; DICH: dichotomizing.

\section{Competing interests}

The authors declare that they have no competing interests.

\section{Authors' contributions}

$\mathrm{EB}, \mathrm{KM}$ and MRE originated the idea for this study, did the research proposal, data analysis and prepared the manuscript. BS helped and edited the final version as the medical consultant. All authors read and approved the final manuscript.

\section{Acknowledgements}

This study was financed by a grant from Tehran University/Medical Sciences. The authors acknowledge the National Health Survey for their data, coordinated at the Department of Biostatistics, School of Public Health and Institute of Public Health Research, Tehran University/Medical Science, Iran.

\section{References}

I. Zhao LP, Kolonel LN: Efficiency loss from categorizing quantitative exposures into qualitative exposures in case-control studies. American Journal of Epidemiology 1992, I 36:464-474.

2. MacCallum RC, Zhang S, Preacher KJ, Rucker DD: On the practice of dichotomization of quantitative variables. Psychological Methods 2002, 7:19-40.

3. Cohen J: The cost of dichotomization. Applied Psychological Measurement 1983, 7:249-253.

4. Greenland S: Avoiding power loss associated with categorization and ordinal scores in dose-response and tread analysis. Epidemiology 1995, 6:450-454.

5. Austin PC, Brunner LJ: Inflation of the type I error rate when a continuous confounding variable is categorized in logistic regression analyses. Statistics in Medicine 2004, 23: I I59-I I 78.

6. Vargha A, Rudas T, Delaney HD, Maxwell SE: Dichotomization, partial correlation, and conditional independence. Journal of Educational and Behavioral Statistics 1996, 21:264-282.

7. Maxwell SE, Delaney HD: Bivariate median splits and spurious statistical significance. Psychological Bulletin 1993, I I3:18|-190.

8. Streiner DL: Breaking up is hard to do: the heartbreak of dichotomizing continuous data. Can J Psychiatry 2002, 47(3):262-266.

9. Chen $\mathrm{H}$, Cohen $\mathrm{P}, \mathrm{Chen} \mathrm{S}$ : Biased odds ratios from dichotomization of age. Statistics in Medicine 2007, 26:3487-3497.

10. Goldwasser MA, Fitzmaurice GM: Multivariate linear regression analysis of childhood psychopathology using multiple informant data. International Journal of Methods in Psychiatric Research 200I, 10:1-10.

II. Moser BK, Coombs LP: Odds ratios for a continuous outcome variable without dichotomizing. Statistics in Medicine 2004, 23:1843-60.

12. Ogden CL, Carroll MD, Curtin LR, McDowell MA, Tabak CJ, Flegal $\mathrm{KM}$ : Prevalence of overweight and obesity in the United States, 1999-2004. JAMA 2006, 295(13):1549-55.

13. Flegal KM, Caroll MD, Kuczmarski RJ, Johnson CL: Overweight and obesity in the United States: prevalence and trends, 19601994. Int J Obes 1998, 22:39-47.

14. Lewis $\mathrm{CE}$, Jacobs DR, McCreath $\mathrm{H}$, et al.: Weight gain continues in the 1990s: 10 year trends in weight and overweight from the CARDIA Study. Am J Epidemiol 2000, I5 I(I2): I I72-8I.

15. Bagust $A$, Roberts $B L$, Haycox $A K$, Barrow $S$ : The additional lost of obesity to the health service and the potential for resource savings from effective interventions. Eur J Public Health 1999, 9:258-64.

16. Klumbien J, Petkeviciene J, Helasoja V, Prattala R, Kasmel A: Sociodemographic and health behaviour factors associated with obesity in adult populations in Estonia, Finland and Lithuania. Eur J Public Health 2004, I 4:390-4.

17. Sarlio-Lahteenkorva $S$, Lahelma $E$ : The association of body mass index with social and economic disadvantage in women and men. Int J Epidemiol 1999, 28:445-9.

18. Laurier D, Guiguet M, Chau NP, Wells JA, Valleron AJ: Prevalence of obesity: a comparative survey in France, United Kingdom and the United States. Int J Obes Relat Metab Disord 1992, 16(8):565-572.

19. Molarius A, Seidell JC, San S, Tuomilehto J, Kuulasmaa K: Educational level, relative body weight, and changes in their association over 10 years: an international perspective from the WHO MONICA Project. Am J Public Health 2000, 90:1260-8.

20. Wamala SP, Wolk A, Orth-Gomer K: Determinants of obesity in relation to socioeconomic status among middle-aged Swedish women. Prev Med 1997, 26:734-44.

21. Jeffery RW, Forster JL, Folsom AR, Luepker RV, Jacobs DR Jr, Blackburn $\mathrm{H}$ : The relationship between social status and body mass index in the Minnesota Heart Health Program. Int J Obes 1989, 13:59-67.

22. Kawada $\mathrm{T}$ : Difference of body mass index stratified by the period of smoking cessation from a cross-sectional study. Arch Med Res 2004, 35: 18I-4.

23. Laaksonen M, Rahkonen O, Prattala R: Smoking status and relative weight by educational level in Finland, 1978-1995. Prev Med 1998, 27:431-7.

24. Rasky E, Stronegger WJ, Freidl W: The relationship between body weight and patterns of smoking in women and men. Int J Epidemiol 1996, 25:1208-12. 
25. Molarius A, Seidell JC, Sans S, Tuomilehto J, Kuulasmaa K: Smoking and relative body weight: an international perspective from the WHO MONICA Project. J Epidemiol Community Health 1997, 5 I:252-60.

26. Jeffery RW, Rick AM: Cross-sectional and longitudinal associations between body mass index and marriage-related factors. Obes Res 2002, 10:809-I5.

27. Sobal J, Rauschenbach B, Frongillo EA: Marital status changes and body weight changes: a US longitudinal analysis. Soc Sci Med 2002, 56: I543-55.

28. Griffiths $P$, Bently M: Women of higher socio-economic status are more likely to be overweight in Karnataka. India Eur J Clin Nutr 2005, 95: 1217-20.

29. Bostrom G, Diderichsen F: Socioeconomic differences in misclassification of height, weight and body mass index based on questionnaire data. Int J Epidemiol 1997, 26:860-6.

30. Kuskowska-Wolk A, Bergstrom R, Bostrom G: Relationship between questionnaire data and medical records of height, weight and body mass index. Int J Obes Relat Metab Disord 1992, I6(I): I-9.

\section{Pre-publication history}

The pre-publication history for this paper can be accessed here:

http://www.biomedcentral.com/1471-2288/8/78/prepub

Publish with Bio Med Central and every scientist can read your work free of charge

"BioMed Central will be the most significant development for disseminating the results of biomedical research in our lifetime. "

Sir Paul Nurse, Cancer Research UK

Your research papers will be:

- available free of charge to the entire biomedical community

- peer reviewed and published immediately upon acceptance

- cited in PubMed and archived on PubMed Central

- yours - you keep the copyright 